\title{
Conversaciones y percepciones de niños y niñas en las narrativas antropológicas
}

Diana Milstein

Doctora en Antropología Social por la Universidad de Brasília. Profesora Asociada de la Facultad de Ciencias de la Educación, Universidad Nacional del Comahue y Centro de Antropología Social - IDES - de la República Argentina

Resumen Como parte de mi trabajo de campo durante un proceso de investigación etnográfica en educación en la localidad de Villa La Florida en Quilmes, al sur del Gran Buenos Aires, Argentina, incorporé a un grupo de niños y niñas en calidad de "informantes", investigadores y autores. Centré mi mirada en cómo ellos percibían el mundo social dominado por el sentir, decir y hacer de los adultos; estuve atenta a cómo contaban su propia historia usando sus propios modos; y trabajé junto a ellos las versiones que construyeron sobre la vida del barrio y de la escuela que, de diversas maneras, se entretejían con sus narrativas. En este artículo narro esta experiencia y analizo cuestiones referidas a las particularidades de sus miradas y narrativas. Pongo especial atención en los modos en que los niños entrelazaban percepciones e interpretaciones del mundo social con el que convivían y enfatizo la relevancia que tuvo incluir en la narrativa etnográfica sus voces. Intento así colocar esta práctica etnográfica como contenido para discutir el estatuto del discurso de los niños en las narrativas antropológicas.

Palabras claves: etnografía; trabajo de campo con niños; narrativas antropológicas.

\section{I - Una idea que surgió sobre la marcha}

Como parte de mi trabajo de campo durante un proceso de investigación etnográfica en educación en la localidad de Villa La Florida, situada en Quilmes (municipio situado al sur del Gran Buenos Aires), incorporé a un grupo de niños y niñas en calidad de "informantes", investigadores y autores. Centré mi mirada en cómo ellos percibían el mundo social dominado por el sentir, decir y hacer de los adultos; estuve atenta a cómo contaban su propia historia usando sus propios modos; y trabajé junto a ellos las versiones que construyeron sobre la vida del barrio y de la escuela que, de diversas maneras, se entretejían con sus narrativas. Esta experiencia me permitió tener una aproximación más concreta y minuciosa de la escuela y de los espacios y las relaciones sociales de la localidad. Con sus puntos de vista, ellos iluminaron y nutrieron mi comprensión de la vida de las familias, del mapa social de la localidad, de las percepciones que se tienen desde afuera del espacio escolar sobre la escuela y de un sinfín de episodios concretos que acontecieron.

Desde el inicio de mi trabajo de campo, en abril de 2004, concurría a la escuela y procuraba intercambiar diálogos con los adultos y con los niños y las niñas, participando en distintas actividades que se desarrollaban en la escuela: clases, reuniones, recreos, actos, almuerzos, etc. 
Como suele ocurrir, fui adquiriendo un mayor acercamiento con algunas personas adultas con quienes los diálogos se tornaban cada vez más fluidos e inclusive más íntimos. Con los alumnos y las alumnas era un poco diferente. Por ejemplo, podía pasar un recreo casi completo sin que ninguno se acercara a hablarme o tener varios chicos alrededor mío haciendo preguntas, contando algún chisme, un chiste o algo que les había sucedido. Mientras ocurrían estos intercambios alguna opinión, gesto o historia breve me dejaba pensando y me estimulaba a escribir largas notas en mi cuaderno. Sin embargo, en un primer momento fue escaso el valor que le concedí a esas interacciones con los niños, dado el lugar que yo les otorgaba como interlocutores en mi tarea. Mi preocupación consistía en observar las prácticas escolares en su dimensión política, lo que me orientaba -hoy diría de manera reduccionista- en dirección a aquello que hacían y decían los adultos. Me costaba percibir que en varias oportunidades, $\mathrm{y}$ a veces sin que me diera cuenta totalmente en el momento, los comentarios de los niños contaban situaciones y mostraban conocimientos relativos al tema que me interesaba.

George Balandier (1994, p. 12) refiriéndose a las "cortinas ideológicas que nos impiden ver", le asigna al extrañamiento "una virtud desoxidante" que posibilita advertir que lo que se presenta como paradójico, resulta "la más viva manifestación del orden de las cosas y de la naturaleza del poder". En mi caso, ese efecto lo produjeron muchos de los párrafos de mis escritos en los que "hablaban" niños y niñas.

En mis notas percibí que lo más interesante que ellos me aportaban no eran informaciones o datos puntuales, sino su modo de transmitirlas, las asociaciones que hacían y lo que señalaban u observaban como relevante en lo que contaban. A través de sus relatos, las vidas familiares y la vida escolar ingresaban en un tono de relato claro, diáfano y muy vivaz. De este modo, yo lograba entender desde una perspectiva distinta algunas situaciones y ciertos modos de relación, y llenar espacios vacíos en relatos de los adultos.

$\mathrm{Si}$ bien mi foco no estaba en las representaciones sociales y culturales de los/as niños/as ni en las particularidades de su vida social y cultural, resultó imprescindible reflexionar epistemológica y metodológicamente para imaginar cómo darle un lugar central a las narrativas de los alumnos y alumnas en mi etnografía.

\section{Hacia la elaboración y la fundamentación de la idea}

En tiempos en que aún no se hablaba de antropología de la niñez, como es sabido, algunos antropólogos abordaron la infancia. Entre ellos, están: los trabajos en los que Margaret Mead caracteriza rasgos, describe y compara los comportamientos y las representaciones de niños/as de distintas aldeas de Samoa y Nueva Guinea y desarrolla comparaciones con aspectos de la socialización de los niños de la sociedad norteamericana (1932, 1954, 1985); los trabajos de antropólogos como Iona y Peter Opie $(1969,1977)$ y John y Beatrice Whiting (1975) que desarrollaron comparaciones entre modos de socialización en diferentes culturas y los estudios acerca de los juegos infantiles de Marcel Griaule ${ }^{1}$. Estos trabajos han mostrado de manera muy convincente la gran variación cultural existente respecto a lo que se considera que son los niños y las niñas, a los modos de crianza, a lo que los adultos esperan de ellos/as, al lugar social que ocupan, a los modos de relación entre pares y con los adultos/as, etc. Estos aportes han operado como un argumento muy fructífero en oposición a las nociones que consideran a la infancia como un hecho fundamentalmente natural y biológico y han enriquecido una mirada crítica sobre el concepto occidental de la infancia, surgida de la propia comparación. Estudios posteriores en ciencias sociales y humanas han continuado trabajando en este sentido, mostrando la relatividad histórica y contextual de la infancia, dando lugar así a la introducción de la noción de infancias ${ }^{2}$. Desde esta afirmación de existencia de infancias se ha planteado y sostenido la necesidad de comprender a los niños como "sujetos"-en el sentido de humanos y sujetados- a sus propios contextos sociohistóricos. Esta comprensión ha abierto un debate en torno al status que se le otorga a los niños como sujetos sociales. No alcanza con situarlos en su contexto histórico, también es necesario tomar en cuenta que sus actividades implican modos de agenciamiento. En esas actividades, siempre están implicados los usos simbólicos que cada sociedad, en diferentes momentos históricos, realiza del concepto de niño y de su lugar con relación al adulto ${ }^{3}$. Más aun, cuando en una sociedad determinada se caracteriza y define al niño y/o a los niños, siempre es en relación con los adultos.

1 Aludo a sus estudios sobre juegos de los niños entre los Dogon que son inaugurales en cuanto a la consideración de los niños como sujetos empíricos de la observación participante para comprender la vida social y cultural de un pueblo.

2 El trabajo fundacional de Philippe Arièh (1973) provee las bases que ha permitido la relativización del concepto de infancia, su análisis en términos de su contexto social y el distanciamiento de modos propios de un reduccionismo naturalista.

3 James, Jenks y Prout (1994, p. 26-34) plantean la existencia de cuatro modos conceptuales de construir sociológicamente a la infancia como categoría teórica que encuadran en lo que denominan paradigma emergente de la Sociología de la infancia y plantean perspectivas críticas en torno a las posibilidades teóricas y metodológicas de comprender a los niños en su lugar de sujetos y actores sociales en nuestras sociedades contemporáneas. 
Decir qué es un niño es al mismo tiempo decir qué es un adulto, inclusive, al decir lo que el adulto no es. Decir qué es un niño es también decir cómo nos volvemos adultos, y decir lo que es un adulto es decir qué relación tenemos con nuestra infancia (Kennedy, 1999, p. 82)

No es una novedad argumentar que, en la mayoría de los casos, tanto en discursos del sentido común como científicos, se caracteriza a los niños desde una predefinición de los adultos, y su vida social, desde una predefinición de la vida social de los adultos. Sin embargo, también se ha desarrollado una tendencia opuesta a ésta, que procura comprender a las infancias, a los niños y a las niñas a partir de lo que hacen y dicen, inclusive para entender a través de ellos aspectos de la vida de los adultos.

Mary Ellen Goodman (1972) sostenía la importancia de considerar a los niños como informantes calificados en los trabajos antropológicos, porque entendía que ellos también eran miembros de la sociedad y contaban con un manejo particular de la cultura. Refiriéndose a un estudio comparado que hizo con otros especialistas con niños de Japón, decía que las preguntas que se les hacían se orientaban hacia la conciencia social. Querían saber lo que ellos veían cuando miraban hacia el amplio universo social que los rodeaba y qué pensaban al respecto. Este fue un trabajo inaugural en la búsqueda por aprehender el punto de vista de los niños sobre la realidad social.

Sin embargo, este interés recién adquirió mayor relevancia en la década del ochenta en que comenzó a definirse con claridad un campo de la sociología y la antropología de la niñez. No obstante, procurar entre los niños y las niñas perspectivas para la comprensión del mundo adulto sigue sin ser lo más frecuente, cuestión que considero vinculada al conjunto de ambivalencias, ambigüedades y contradicciones que continúan marcando las representaciones sociales -de sentido común y académico/científicas- de los niños y de las niñas.

Christine Toren (1993) desarrolló una argumentación muy sólida en este sentido. Sostuvo que la falta de interés de la antropología contemporánea en los niños radica en que los antropólogos asumen que el punto final de la socialización es algo conocido y no abierto, como realmente es. Entendió que no toman en cuenta que la cognición humana es un proceso histórico y que "todos los procesos cognoscitivos implican la localización de las personas en el mundo cuyo sentido está mediado por su articulación con las relaciones complejas a las que describimos bajo la rúbrica de 'parentesco', 'religión', 'economía política', etc.” (Toren, 1993, p. 461). En este sentido, consideró fundamental poner "el foco en los niños como sujetos y objetos de la historia y en los procesos a través de los cuales ellos constituyen sus conocimientos del mundo" (p. 462) para analizar rasgos medulares de la vida adulta. Esta autora, como parte de su investigación en Fidji -Melanesia-, estudió los significados de los niños fidjianos respecto a la noción de jerarquía y los comparó con la de los adultos, encontrando una suerte de inversión de sentido. Este, así como otros hallazgos de su largo e intenso trabajo etnográfico con niños, la condujo a considerar la relevancia de los conocimientos y las nociones que orientan las vidas de los niños para entender completamente las relaciones entre adultos.

Así, la necesidad de incorporar la perspectiva de los niños y de las niñas en un trabajo etnográfico responde a un supuesto elemental: lo que las personas piensan, sienten, perciben e interpretan acerca de la realidad forma parte de la propia realidad. Los niños y las niñas por lo general son parte de los grupos sociales que se estudian y, sin duda, integran como grupo la vida social de las escuelas. De ahí que sus puntos de vista y perspectivas sobre lo que acontece también constituyan la realidad social que etnográficamente se procura conocer y comprender. A esta altura del avance de los estudios en antropología de la niñez, está sólidamente demostrada la necesidad de acceder a la perspectiva de ellos para comprender aspectos de la vida social infantil y nadie duda de la necesidad de contar con la perspectiva de los adultos para un estudio sobre la niñez. De modo similar, considero que debe incorporarse el conocimiento de los niños/ as para la comprensión de aspectos de la vida social de los adultos ya que, tanto en un caso como en el otro, comparten de manera intensa -cuantitativa y cualitativamente hablando- sus vidas cotidianas.

En función de incorporar a mi trabajo antropológico lo que sabían y conocían los niños y las niñas, además de darles el lugar y el status similar al que tenían los sujetos adultos de mi investigación, opté por organizar un grupo pequeño para realizar una parte de mi etnografía en colaboración con los niños. Ellos/as, en grupo y bajo mi coordinación, hicieron trabajo de campo, de reflexión, de análisis y producción de texto. Los datos, las informaciones y los documentos surgidos del trabajo de campo ingresaron como parte de la etnografía que presenté como tesis de doctorado ${ }^{4}$.

\section{La experiencia se lleva a cabo}

Inicié mi trabajo de campo a fines de abril de 2004 en una escuela primaria estatal argentina situada en 
la localidad de Villa La Florida, Partido de Quilmes, veinticinco kilómetros al sur de la ciudad de Buenos Aires. Estaba interesada en estudiar la dimensión política de las prácticas escolares de escuelas primarias estatales, comprendidas en términos de las relaciones entre el Estado y la sociedad, en las condiciones de desorganización y precariedad de la vida cotidiana escolar, derivadas de la crisis económica, social y política de los años 90 en Argentina. Para ello me propuse focalizar las prácticas vinculadas a pugnas por algún tipo o forma de poder, modos de control y conflictos, tal como eran protagonizadas en la escuela por el conjunto de los empleados estatales -docentes y auxiliares-, los integrantes de la cooperadora y los familiares adultos de los niños que participaban de algún modo en la vida escolar. Desde la perspectiva de mi estudio, examinar las prácticas escolares en su dimensión política era, por un lado, considerar a la escuela como un espacio social para analizar procesos políticos sin reducirlos a dimensiones pedagógicas, administrativas y/o de legislación; y, por otro, situarlos dentro de una trama compleja de prácticas que nunca quedan cerradas en la escuela misma y que adquieren significados diversos, a veces contradictorios entre sí, en la medida que se despliegan entre el afuera y el adentro escolar (Nespor; 1997, p. xii). Ambos aspectos fueron muy enriquecidos por lo que aportaron los dos períodos de trabajo etnográfico con niños/as que ocuparon una parte de mi trabajo de campo durante 2004 y otra durante 2005.

El trabajo etnográfico con niños/as que realicé consistió en integrar a un grupo pequeño de alumnos de la escuela -siete durante el primer año y seis durante el segundo- como colaboradores. La particularidad que tuvo esta experiencia presentó distintas dimensiones. En primer lugar los/as colaboradores fueron niños/as; en segundo lugar se conformaron como grupo de colaboración; en tercer lugar actuaron como interlocutores, entrevistadores y observadores participantes; en cuarto lugar organizaron los testimonios de otros y los propios y produjeron colectivamente textos.

El conjunto de actividades estaba encuadrado institucionalmente en la escuela -respaldaba lo que realizábamos, utilizamos sus instalaciones, los docentes y el personal de auxiliares colaboraban y acompañaban-, pero era externo con relación a los parámetros establecidos por el currículo, la distribución espacial y temporal. Nos reuníamos una o dos veces por semana, a veces durante dos horas y otras veces las actividades nos llevaban entre cuatro y cinco horas. Usábamos algún día del fin de semana y horarios de tarde, luego de finalizada la jornada escolar.

Ambos grupos realizaron actividades de observación, observación participante, entrevistas grabadas, registro fotográfico, diseño de planos de la localidad, conversaciones grupales, lectura y análisis de los registros grabados y de las fotografías, tareas de selección de textos y de escritura para la confección de una publicación. Conversar, preguntar y escuchar; observar, mirar, sacar fotos y grabar; dibujar y pintar; leer y escribir fueron las actividades fundamentales que desarrollaron ambos grupos. Los niños y las niñas colaboraron con mi etnografía relatando hechos y situaciones, dándome sus pareceres y puntos de vista, haciéndome partícipe de situaciones de sus vidas cotidianas, paseando conmigo por calles y lugares de la localidad, entrevistando a personas adultas y a otros niños/as, leyendo y comentando las grabaciones de las entrevistas y de las reuniones grupales y organizando dos textos que contienen la producción grupal de cada uno de los grupos.

El conjunto de actividades del primer grupo estuvo orientado, tal como se los planteé desde la primera reunión, a conocer qué pensaban los vecinos acerca de ese lugar y la escuela 40, cómo era antes y cómo era ahora.

Las primeras reuniones las destinamos a conversar sobre los lugares que visitaríamos, las personas que entrevistaríamos, las tareas que cada uno desarrollaría. También en grupo, se realizó el dibujo del plano del barrio tal como era recordado. Esta actividad dio lugar a conversar sobre lo que cada uno conocía, a integrarme a mí al lugar de ellos/as, a producir una dinámica de trabajo en la que cada uno fue encontrando su papel. El grupo coincidió en seleccionar como primer lugar a la plaza de Villa La Florida, situada frente a la escuela. La idea fue visitarla durante las tardes de los fines de semana en los que funcionaba una feria y entrevistar a los feriantes y a las personas que estuvieran allí paseando y comprando.

Tomando en cuenta que esa plaza era uno de los lugares considerados "peligrosos" por la mayoría de los adultos con los que hasta ese momento yo había dialogado -y que estos niños y niñas conocían esa opinión, que más tarde ellos mismos confirmaron que era generalizada-, esta elección anticipó una orientación en términos de motivaciones, preocupaciones e intereses de este grupo hacia su mundo cotidiano y hacia las actividades que llevaron a cabo. Al seleccionar la plaza como espacio privilegiado para conocer a la gente del barrio, desacreditaron en principio la idea "adulta" de peligrosidad indiferenciada. Lo interesante fue que, posteriormente, cuando visitamos la plaza, ellos me explicaban, utilizando relatos de lo que a ellos/as les había sucedido, las razones por las que esa plaza era peligrosa y, al mismo tiempo, las razones por las que se podía estar y disfrutar ese lugar. Luego, lo que contestaban y relataban las personas que los chicos entrevistaron también mostraron estas dos caras, pero en su mayoría, los relatos de los adultos aludían a un pasado en el que la plaza no presentaba peligros de ningún tipo y a un presente en el que el peligro estaba en todas partes -por la presencia 
de algunos grupos de jóvenes, por lo que hacían, por cómo actuaban, por los objetos que se encontraban, etc. Los objetos y las personas que allí estaban tenían una presencia incuestionable para adultos y niños, pero estaban organizados con otro orden y producían significados que se diferenciaban entre sí.

Sin ninguna pretensión de explicar exhaustivamente el registro de estas diferencias, me arriesgo a plantear que uno de los elementos más evidentes de esta diferencia de visiones, radica en la utilización del organizador espacial o temporal y otro, en el peso valorativo que tenían las propias vivencias. Los/as adultos/as realizaban un corte temporal entre un antes no amenazante y un ahora peligroso; el organizador temporal operaba para cualificar de un modo generalizador un espacio en sus aspectos físico y social; en cuanto a la valoración, lo mejor estaba depositado en los recuerdos de sus infancias y juventudes. Los/as niños/as diseñaban en sus narrativas lugares con fronteras relativamente precisas dentro de la plaza que separaban lo amenazante de lo no peligroso siempre situados en un tiempo presente, y la valoración de cada lugar se vinculaba a sus propias vivencias.

Así, mi trabajo antropológico se vio enriquecido con estos modos diferenciados de dar sentido a lo que significaba esa plaza, dialogando entre sí. El modo en que estos diálogos se constituyeron como parte del conocimiento que construyó el grupo de niños/as quedó expresado, tal como lo mostraré más adelante, en los textos producidos como etapa final de este proceso etnográfico. Así como sucedió con la plaza, otros temas claves de la vida social de esa localidad -las familias, los trabajos, las divisiones sociales dentro de la localidad, entre otros- mostraron, por un lado, las diferencias en las visiones de los niños y los adultos y por otro, la capacidad fructífera del diálogo entre esas visiones para desarrollar los conocimientos.

Reuní el segundo grupo en agosto de 2005 -tres de los integrantes fueron los mismos- y realizamos un proceso similar al del grupo anterior en cuanto al propósito de conocer y registrar versiones acerca de la vida en la localidad y la escuela, al modo de funcionamiento, al tiempo dedicado y a las diferentes tareas y actividades desarrolladas. Lo que estableció desde el inicio una diferencia con el proceso anterior fue que recogieron relatos y opiniones de otros niños y niñas. Entrevistaron a otros alumnos de la escuela, a chicos que iban a otras escuelas y a otros que no asistían a ninguna escuela. Algunas entrevistas las hicieron en la escuela, otras en la plaza, en un shopping center y también en casas. En esta segunda experiencia dialogaron entre sí versiones de diferentes niños y niñas y relatos biográficos que se combinaron con los de los integrantes del grupo. En esta combinación de versiones que surgían en diferentes diálogos, conversaciones y reuniones ingresaba intensamente lo que hacían, pensaban, sentían y opinaban los adultos próximos -especialmente familiares y vecinos- a través de temas que solían reiterarse.

Un ejemplo fue el ingreso del tema de la política. Apareció en varias conversaciones muy diferentes y alrededor de cuestiones distintas. En una oportunidad, casualmente, surgieron comentarios a raíz de las propagandas callejeras sobre lo que se contaba en las casas, las acusaciones hacia los diferentes candidatos, lo que comentaban en programas de televisión y muchos de los chistes que circulaban. En otras ocasiones, se habló del tema porque varios chicos del grupo y entrevistados comentaron que familiares trabajaban en la política; y en otras surgió a partir de comentarios de familiares y personas conocidas que "están en un Plan [subsidios gubernamentales para personas sin trabajo] y la que les dio la mercadería les dijo que tenían que votar a Cristina". En este caso, a diferencia de lo que analicé antes respecto a la plaza, lo que advertí fue la coincidencia entre versiones. Las informaciones que se iban agregando abonaban un núcleo significativo común en torno a la política que escuché muchas veces en la escuela y fuera de la escuela, en esa localidad y en otras, y también a través de los medios de comunicación. Esta otra dimensión del trabajo con los niños y sus narrativas no sólo resultó evidentemente muy enriquecedora para mi etnografía, sino que además me ayudó a entender mucho más acerca de quienes eran estas personas con las que estaba trabajando, distanciándome de modos estereotipados de entender a los/as niños/as. Una observación similar hizo un grupo de investigadores que desarrolló un estudio con alumnos de 24 escuelas públicas en Rio de Janeiro para conocer cómo los niños ven la ciudad. Ellos recogieron alrededor de 3000 cartas y dibujos realizados por alumnos de escuelas primarias sobre la vida en la ciudad a partir de diferentes temas. Entre las conclusiones, señalaron que los alumnos reproducían los mismos puntos de vista difundidos entre los sujetos adultos de la localidad. En sus cartas y dibujos no sobresalían aspectos o rasgos muy innovadores, sino que encontraban perspectivas y miradas relativamente convencionales (Vogel y otros; 1995, p. 134).

\section{Al final, dos textos}

Durante el proceso etnográfico los chicos fueron elaborando y construyendo relaciones, perspectivas, percepciones y visiones que, en parte, quedaron inscriptas en dos textos, uno terminado en noviembre de 2004 y el otro en noviembre de 2005. El hecho que al final haya textos no debe dar lugar a una visión simplista y lineal acerca de cómo fueron los 
procesos de construcción de los relatos que -en parte- quedaron escritos. En función de dar cuenta de estos procesos, voy a dividirlos -inevitablemente de manera esquemática- en momentos que distingo por características de las narrativas y por las actividades desarrolladas. Estos momentos precedieron y acompañaron la producción de los textos.

Narrativas orales: Son los momentos en que todo ocurría en lenguaje oral y gestual. Las acciones fundamentales eran contar, comentar, opinar, preguntar, escuchar, reír, gesticular, mirar, acercarse, alejarse, grabar. Estos momentos acontecían durante las reuniones, salidas y paseos.

Narrativas en imágenes 1: Son los momentos en que todo ocurría con dibujos y fotografías. Las acciones fundamentales eran dibujar, pintar y mirar planos, y tomar fotografías. Cada uno de los grupos realizó el dibujo de un plano en grupo y en varias sesiones. Los planos se dieron por finalizados prácticamente al terminar el proceso completo. Las fotografías las tomaron en forma individual. Registraron lugares y personas de acuerdo al entusiasmo del momento.

Transcripción de narrativas: Este momento fue protagonizado sólo por mí. Consistió en escuchar los casetes grabados y escribirlos de la manera más parecida posible a lo que se hablaba. Produje así un primer texto.

Narrativas escritas 1: Los chicos recibieron las transcripciones que yo hice como texto impreso y las leyeron indicando lo que les parecía importante. Se discutieron criterios referidos a lo importante, mostrando los fragmentos que cada uno señalaba y explicando el por qué. Se comentaron los temas que surgían de esas lecturas. Se definieron los temas que interesaba que estuvieran en cada uno de los textos. Se organizó un índice. Se marcaron fragmentos con distintos colores en los textos escritos, de acuerdo a su correspondencia con el tema. Definieron el título.

Narrativas escritas 2: el texto del 2005 también incluyó texto escrito por los chicos. Luego de haber definido los temas que organizaban el índice, algunos de ellos escribieron comentarios sobre cada uno de los temas, que ingresaron en el texto sin ninguna variante.

Narrativas en imágenes 2: Los rollos de fotografías fueron revelados y se realizaron copias de todas las fotos. Los chicos las miraron y realizaron diversos tipos de selecciones: fotos para ellos, para mirar con sus familias, para mostrar en la escuela, para regalar, para colocar en el texto. Mi intervención en algunas de estas selecciones fue decisiva. Por una cuestión de índole económica, les impuse reducir la cantidad seleccionada para los textos y para regalar. En cuanto a los planos, eran de un tamaño grande-ocupaban alrededor de seis mesas de las que usan los alumnos en las aulas- y para su incorporación a los textos tuvimos la colaboración técnica de una fotógrafa.

Narrativas escritas 3: Yo transcribí los fragmentos seleccionados y los acomodé de acuerdo a los temas ya estipulados. Transcribí el índice. Realicé una impresión en forma de libro utilizando la dimensión de media página A4 Los chicos leyeron esta segunda transcripción, corrigieron errores, quitaron fragmentos, eligieron lugares para colocar las fotografías.

Finalmente con la colaboración de una editora se hizo la impresión de la primera versión de ambos libros en papel común y los chicos lo presentaron en ocasión de una fiesta que se organizó en la escuela. El primer libro, titulado Averiguando algo más. Leyendo la historia de nuestro barrio y de nuestra escuela, estaba organizado bajo cinco subtítulos: Conocemos la plaza, Anécdotas de los bomberos, Fernando: nuestro "patriarca", Nuestra escuela y ¿Cómo se siente el barrio? El segundo libro lo denominaron Así vemos La Florida y lo organizaron seis partes: Las Escuelas, Los Lugares, Las Familias, Los trabajos de los Padres, La Política, Las Leyendas de Miedo.

La historia de estos textos aun continúa, pero aquí me interesa detenerme para caracterizar esta narrativa escrita que produjimos durante el proceso etnográfico con niños/as.

$\mathrm{Al}$ referirme a la experiencia con el primer grupo, mencioné la importancia que tuvo desde el inicio la plaza que está en frente de la escuela 40. La localidad tiene otros tres espacios verdes, pero el único reconocido como "la plaza" por sus pobladores es éste. Durante todo el proceso etnográfico fue un tema que mantuvo relevancia constante en cuanto al interés del grupo de chicos. Esta relevancia se manifestó en la cantidad de fotografías y de texto, así como en la dedicación que pusieron al dibujarla en el primer plano. El espacio que ocupa en la representación pictórica es comparativamente muy grande respecto a los otros elementos representados, podría decirse que es proporcional al lugar que ocupó en la versión que los niños organizaron sobre la localidad. Es el primer tema del libro y tiene más texto escrito que los demás. Las fotografías que seleccionaron para esta parte del texto, fueron explícitamente las que ellos consideraron que "se veía relinda la plaza". En primera instancia seleccionaron once, pero luego, al tener que reducir a dos la versión de la plaza en imágenes, seleccionaron la que tiene en el centro el altar de la Virgen del Rosario y otra cuyo primer plano son plantas floridas. Lo particular de esta última foto es que esas plantas parecen pertenecer a la plaza, pero en realidad son de un puesto de una feriante que vendía flores. Cabe aclarar que en muchas conversaciones la escasa cantidad de plantas y flores que tenía la plaza era motivo de preocupación general. La pers- 
pectiva narrativa de los niños resolvió con esta foto esa preocupación general:

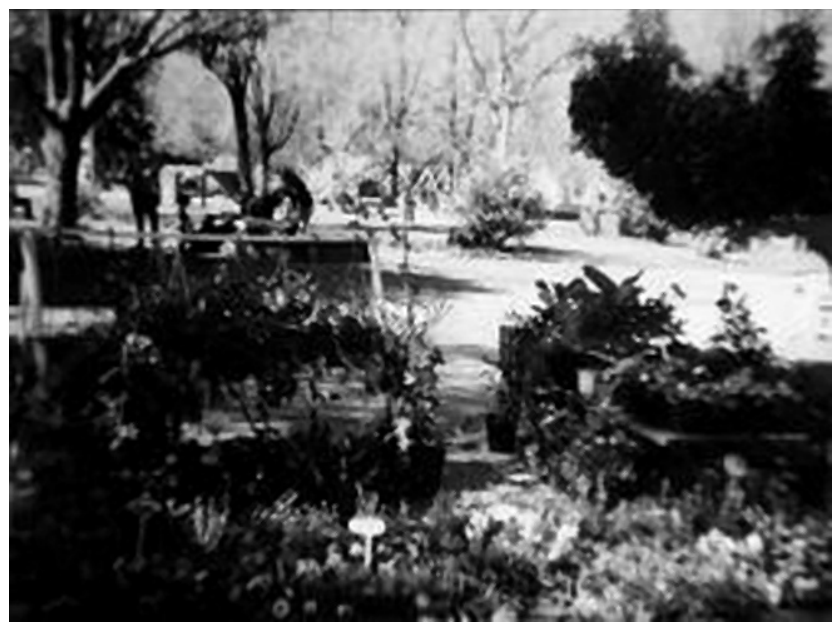

En cuanto a los fragmentos de texto seleccionados fueron organizados de acuerdo a subtemas que quedaron reflejados en los subtítulos y en el contenido seleccionado. La primera parte la denominaron "Antes de ser plaza" y allí reunieron frases como: Un yuyal, o un potrero, había una canchita y un cerquito, pero había un yuyal altísimo; Era un campito, pero no un yuyal, un campito le decíamos. A continuación colocaron el título "Así se construyó" que contenía frases como la siguiente: A partir de un emprendimiento que tuvieron varias personas, se hizo una comisión con gente muy importante. Se hizo una comisión de mujeres y una comisión de hombres. Y fue inangurada con toda la pompa barrial. Luego el libro continuaba contando "Cómo era y cómo es": Antes la plaza estaba muy linda, había una fuente, estaba toda iluminada, tenía flores lindas. Era muy linda, pero se arruinó. La plaza siempre fue el centro de reunión de la Florida. Teníamos una plaza muy linda, o sea, la plaza es la misma lo que cambió es lo que teníamos. La última parte la dedicaron a "La feria": Esta feria hace tres años que está funcionando, empezamos con un grupito chiquitito, con mucha vergüenza al principio, vergüenza porque venimos todos de estar trabajando en fábricas, en oficinas, y bueno después te agarra la desocupación, el cierre de fábricas. $Y$ entonces dijimos bueno, armemos una pequeña feria y empezamos.

El contenido del texto tiene una línea temporal que da cuenta del proceso de construcción de ese lugar como plaza, contiene una permanente alusión a la transformación de la vida social en ese lugar, comparaciones entre el pasado y el presente en el aspecto físico y social, y la mayor extensión está dedicada al último tema que es la feria con muchas referencias a la desocupación, al dinero que allí circula, al tipo de relaciones humanas y a los sentimientos que ha generado.

Luego de esta breve presentación de la narrativa escrita de los niños, cabe preguntarse ¿qué características generales tienen los dos textos producidos?
Son libros pequeños por su tamaño y por la cantidad de hojas escritas e ilustradas que contienen. Están confeccionados en su totalidad en hojas blancas comunes para impresión. Todas las ilustraciones están en colores. Sus tapas están ilustradas y llevan impreso el título. En su primera hoja están los nombres y apellidos de los autores y un pie de imprenta (como la impresión fue artesanal y sin intervención de una editorial, figura como editora la escuela). En su segunda hoja está escrito el índice. Al final figuran datos de los autores.

En lo que se refiere al género, no son textos etnográficos, tampoco testimoniales, a pesar de que su contenido son fragmentos de testimonios orales. Y tampoco tienen la forma y el contenido propios de una redacción o composición escolar.

Si entendemos a la tarea del etnógrafo como la de "un articulador de intertextualidades, un artesano que teje su discurso con fragmentos textuales preexistentes" (Segato, 1999, p. 12), estos textos deben considerarse construidos y producidos a partir de una actitud propia de un etnógrafo. En este sentido, es manifiesta la voluntad de registrar versiones de los otros acerca de una localidad pequeña en su dimensión y utilizando lo que podríamos denominar de un presente etnográfico. Resulta clara la relación de fragmentos de los discursos orales de los otros y de sí mismos -colocados en tercera persona- con una organización que ofrece versiones inteligibles de la vida social local. Además, los fragmentos seleccionados tienen un tono descriptivo y narrativo logrado a través de una combinación de versiones narrativas y de imagen, cuya intención fue comunicar una visión comprensiva de la vida social local.

Para finalizar, quiero enfatizar la centralidad que tuvieron las narrativas producidas durante el proceso de trabajo etnográfico con los/as niños/as, expresadas en sus diversas formas -orales, en imágenes, escritas-, en tanto modos de análisis e interpretación cruciales para mi etnografía. Estas experiencias me dejaron una gran enseñanza con respecto a la necesidad de contar con interpretaciones construidas de manera colectiva con niños y niñas en el campo. En el trabajo con ellos lo fortuito siempre prevaleció frente a lo previsible, la subjetividad del significado de los sucesos se reafirmó sin que ocasionara ningún tipo de desajuste o incomodidad y, los tipos, modelos o caracterizaciones generalizadas no opacaron las versiones distintivas de las individualidades. Así, el esfuerzo por comprender a los/as niños/as, por involucrarme en un trabajo de investigación con ellos/as, dejó una experiencia rica y abundante en conocimientos e interpretaciones, instaló de manera duradera la necesidad de incluir sus discursos en mi narrativa antropológica y redundó en una mayor comprensión de mi misma y de otros adultos. 


\title{
Referencias
}

ARIES, Philippe. História Social da criança e da família. Rio de Janeiro: Guanabara, 1973.

BALANDIER, George. El Poder en Escena. De la representación del poder al poder de la representación. Buenos Aires: Paidos, 1994.

GOODMAN, Mary Ellen. El Individuo y la Cultura. Conformismo vs. Evolución. México/Buenos Aires: Centro Regional de Ayuda Técnica/Agencia para el Desarrollo Internacional (AID), 1972.

KENNEDY, David. Notas sobre a Filosofia da Infancia e a Política da Subjetividade. En: Filosofia e Infancia. Possibilidades de um Encontro. Petrópolis: Vozes, 1999. p. 75-87.

JAMES, A.; JENKS, C. y PROUT, A. Theorizing Childhood. Oxford: Polity, 2004.

MEAD, M. Adolescencia, Sexo y Cultura en Samoa. Buenos Aires: Paidos, 1985.

An investigation of the thought of primitive children with special referent to animism. Journal of the Royal Anthropology, n. 62, p. 173-90, 1932.

y WOLFENSTEIN, M. Childhood in contemporary cultures. Chicago: Chicago University Press, 1954.
MILSTEIN, Diana. A Nação na Escola. Frentes políticas na cena "neutra" da escola argentina. 2007. Disponible en: www. unb.br/ics/dan/tese74.pdf. Acceso en: 18/01/2008.

NESPOR, Jan. Tangled up in school. Politics, space, bodies, and signs in the educational process. New Jersey: Lawrence Erlbaum Associates, 1997.

OPIE, lona y OPIE, Peter. The Lore and Language of School Children Oxford: Oxford University Press, 1977. Chidren's Games in Street and Playground. Oxford: Oxford University Press, 1969.

SEGATO, Rita L. El Vacío y su Frontera: la Búsqueda del otro lado en dos textos argentinos. Série Antropología 257, Universidade de Brasilia, 1999.

TOREN, Christine. Making history: the significance of childhood cognition for a comparative anthropology of mind. Man, New Series, v. 28, n. 3, p. 461-478, september de 1993

WHITING, B y WHITING, J. Children of Six Cultures: A Psychosocial Analysis. Cambridge: Harvard University Press, 1975.

\section{Conversations and perceptions of children in the anthropological narratives}

\begin{abstract}
As part of the fieldwork during my ethnographic research in an educational area of Villa La Florida in Quilmes a district of Buenos Aires, Argentina, I selected a group of children as "informants", researchers, and authors. My view focused on their perception of the social world dominated by adults` ways of feeling, being, and doing things. I was attentive to how they told their stories, using their own words and gestures. We also worked together the versions they constructed about the district's life and school life and how they interwove in different ways with their narratives. In this article, I tell that experience and I analyze issues related to their particular narratives and views. I gave special attention to the way the children link perceptions and interpretations of the social world they live in, and I emphasize how relevant their voices are for the ethnographic narrative. Therefore, this ethnographic practice is used here as an important way of thinking about considering children discourses in the anthropological narratives.
\end{abstract}

Key-words: ethnography, children's field work, anthropological narratives.

\section{Falas e percepcões de crianças nas narrativas antropológicas}

\section{Resumo}

Como parte de meu trabalho de campo durante uma pesquisa etnográfica na área educacional na localidade de Villa La Florida em Quilmes, ao sul da Grande Buenos Aires, Argentina, selecionei um grupo de crianças como “informantes“, pesquisadores e autores. O meu olhar focalizou a forma através da qual elas percebiam o mundo social dominado pelo sentir, falar e fazer dos adultos. Estive atenta à forma como elas contavam a sua própria história, utilizando suas palavras e gestos. Trabalhamos em conjunto as versões por elas construídas sobre a vida do bairro e da escola as quais, de diversas maneiras, se entrelaçam às suas narrativas. Neste artigo, narro essa experiência e analiso questões relativas às particularidades de seus olhares e narrativas. Coloco uma especial atenção nos modos pelos quais as crianças vinculavam percepções e interpretações do mundo social que compartilhavam e enfatizo a relevância de incluir suas vozes na narrativa etnográfica. Assim, essa prática etnográfica é aqui tratada como um eixo importante para a reflexão sobre o estatuto do discurso das crianças nas narrativas antropológicas.

Palavras-chave: etnografia; trabalho de campo com crianças; narrativas antropológicas. 